\title{
The Profile of Green Human Resource Management (GRHM) Practices of Employees in PT. CABOT Indonesia
}

\author{
Wiwik Robiatul Adawiyah ${ }^{1}$ \\ ${ }^{1}$ Department of Management, Faculty of Economy and Business, Trisakti University, Jakarta, Indonesia
}

\begin{abstract}
This study aims to identify GRHM practice from PT employees. Cabot Indonesia. In this study, GRHM practice analysis was identified in general or based on the company's last level of education. The research method used was descriptive quantitative. Respondents who filled out GRHM questionnaires numbered 200 employees of PT. The dominant Cabot Indonesia has the last undergraduate to doctoral education. The instruments used were GRHM practice questionnaires that have good validity and high reliability. Data analysis techniques were descriptive analysis using Ms. Excel. The results show that $30.6 \%$ of employees have GRHM capability in the medium category, while $69.4 \%$ of employees are in the high category. This research's results become a reference in the development of the company's program in creating a clean and green work environment.
\end{abstract}

Keywords: Green Human Resource Management (GRHM), Green Lifestyle, Job Performance, Company Employees

\section{INTRODUCTION}

Management of natural resources can be conditioned with an environmentally friendly work culture as well. One of the management movements to ensure environmental sustainability, especially in the work environment, is GRHM practice. The purpose of the implementation of GRHM is only to improve adaptation in ensuring the ecological quality of the work environment. In addition, this effort can improve the welfare of employees who as production actors who work in a company.
The United States (USA) is the largest food producer in the world. Based on one of the research results on consumers in 68 countries in the US, research on the use of bio-plastics for food significantly impacted the insights of buyers (Confente, Scarpi, \& Russo, 2020). Researchers also showed the influence of self-congruity into moderator variables on the correlation of green self-identity to perceived value in green behavior in his article (Jena \& Sarmah, 2015). Consumer's behavior to use bio-plastic is very influential on consumer self-image how it responds and familiarizes itself in using green products (Confente et al., 2020).

GRHM discussion is a big concern in the world of management. This interesting discussion can not be separated from some other variables related to a company's work environment. Some other variables related to GRHM are very diverse, including green supply chain, ecological health, individual learning motivation, etc. (Jabbour et al., 2016; Joong, Gon, Choi, \& Phetvaroon, 2019; Úbeda-garcía \& Clavercort, 2021; Val \& Paill, 2020). If green human resource management is not considered, it will have an adverse impact on several other factors that will be affected by GRHM itself.

GRHM culture in employees can be the key to successful environmental sustainability (Val \& Paill, 2020). GRHM itself is one of the capabilities that must be embedded in the production actors. Therefore, all employees need to be given training related to GRHM precisely to 
understand the importance of ecologist impact (Bansal and Roth, 2000).

\section{MATERIALS \& METHODS}

The approach used in this research was quantitative using descriptive methods. The samples used were the employees of PT. Cabot Indonesia who were productive with an age range of $18-40$ years. The number of respondents in this study was 200 people. The instrument used was a Green Human Resource Management (GRHM) questionnaire that had validity in a high category with a calculated r-value above 0.40 overall, where the value was above the loading factor value for each item. The validity of the GRHM instrument was well worded and had high reliability. Data analysis techniques used regression analysis with the help of Ms. Excel application.

\section{RESULT}

Based on research questions that mention what percentage of GRHM from employees of PT. Cabot Indonesia, so this section will be discussed related to the results of the research descriptively. The analysis results include a thorough analysis of employee GRHM categories and are continued with identification based on the company's last level of education. Descriptive statistics for the Green Human Resource Management practice variable in this study as a whole can be seen in the following table.

Table 1: Descriptive Statistics of GHRM Practice

\begin{tabular}{|c|c|c|}
\hline No & Question & Mean \\
\hline 1 & I reduce paper usage by using recycled paper in the office & 4,2800 \\
\hline 2 & I do data encoding to my computer to avoid unnecessary printing because the data can be done on my computer or online & 4,2800 \\
\hline 3 & I use bottles used by employees or derived from the pantry & 4,2750 \\
\hline 4 & I read messages sent by email to reduce paper usage & 4,3100 \\
\hline 5 & $\begin{array}{l}\text { I turn off the lights when they are not in use and the computer/printer after business hours for a reduction of electrical } \\
\text { energy }\end{array}$ & 4,2750 \\
\hline 6 & I turn off my computer or other electronic devices while leaving for a while & 4,3250 \\
\hline 7 & I switch to using a laptop through a desktop computer (laptops consume up to $90 \%$ less power compared to desktops) & 4,3150 \\
\hline 8 & I use web or teleconferencing to reduce travel and use of gas transmitter vehicles & 4,2650 \\
\hline 9 & I use transportation facilities that have been provided by the office, such as carpooling, i.e., shuttle & 4,2800 \\
\hline 10 & I use creamer containers, sugar, salt, and coffee that are large or rechargeable, not individual containers for kitchen & 4,3600 \\
\hline 11 & I bring supplies to the office for lunch to reduce packaging waste & 4,2450 \\
\hline 12 & I join a health program for fitness and healthy living employees & 4,3350 \\
\hline 13 & I implement environmentally friendly behavior to promote the green lifestyle & 4,2500 \\
\hline 14 & I use air conditioning when I need & 4,2750 \\
\hline 15 & I made other employees aware of pollution reduction using education and training & 4,2750 \\
\hline 16 & $\begin{array}{l}\text { I follow a formally appointed team that monitor and promote green practices by conducting audits to ensure that standards } \\
\text { were met }\end{array}$ & 4,2600 \\
\hline 17 & I can do such a decomposing and unravelable garbage sorting & 4,3000 \\
\hline 18 & I can separate the types of garbage at work & 4,3750 \\
\hline \multicolumn{2}{|r|}{ Average of Green Human Resource Management Practice } & 4,2933 \\
\hline
\end{tabular}

From the statistics descriptive results for the Green Human Resource Management practice variable, it is known that the average value is 4.2933 . It shows that employees of PT Cabot Indonesia have implemented Green Human Resource Management Practice in the company. The lowest average score is 4.2450 with the statement "I bring supplies to the office for lunch to reduce packaging waste," which means that employees have implemented by bringing their supplies using a place to eat and drink that can be used many times. The highest average score is 4.3750 with the statement "I can separate the types of garbage at work." It indicates that applying by separating the types of organic waste and organic waste should not be mixed into one.

Further analysis is related to the GRHM category in PT employees. Cabot Indonesia needs to be categorized based on the level of education. The picture below shows the frequency and percentage of employees based on the last level of education with low, medium, and high categories. An overview of employee GRHM categories is illustrated in the chart below. 
Table 2: GRHM Profile of Employees

\begin{tabular}{|c|c|c|}
\hline Category & Frequency & Percentage (\%) \\
\hline Low & 0 & $\mathbf{0}$ \\
\hline Medium & 62 & $\mathbf{3 0 , 6}$ \\
\hline High & 138 & $\mathbf{6 9 , 4}$ \\
\hline
\end{tabular}

Based on the table above, employees who have GRHM in the moderate category of 62 people and who have a high category of 138 people will be described in the following chart.

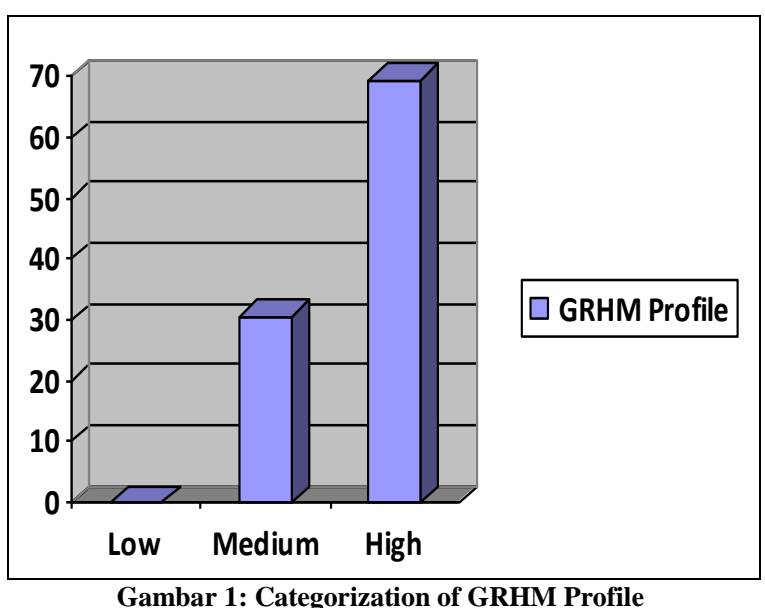

The picture above shows the frequency and percentage of employees who have GRHM in the low, medium, and high categories. It appears that the number of employees who have GRHM in the low category does not exist at all. While employees who have GRHM capability in the medium category have $30.6 \%$ and the high category has $69.4 \%$. Based on the following data, it means that employees at PT. Cabot Indonesia have high GRHM capability. Further analysis of GRHM categorization based on the last education is shown in the table below.

Table 3: GRHM Analysis based on Employee's Last Education

\begin{tabular}{|l|c|c|}
\hline Educational Background & Frequency & Category \\
\hline High School & 0 & - \\
\hline Diploma & 4 & High \\
\hline Bachelor - Doctoral & 196 & Almost All High \\
\hline
\end{tabular}

The table above shows that all employees at PT. Cabot Indonesia has the last education Diploma to Doctoral. Bachelor's degree graduates dominate the company's employees, and almost all employees in this company have GRHM practice in high categories.

\section{DISCUSSION}

Basically, GRHM practices also need to be enforced in the actual school environment (Flax, Kupers, \& Mons, 2020). This is because the road factor can influence schools for children to schools, communities around schools, and other equivalent schools if viewed from their geographical conditions. This geographical review is not only prioritized by the school environment and for children only but also utilized for the comfort of all creatures on earth. Thus, an unpolluted green environment is a primary key in carrying out production and maintaining ecological health for the common good.

The other research considers what GRHM practices of employees need to be identified because GRHM can contribute to human resource policy to protect and protect the environment (Peerzadah, Mufti, \& Nazir, 2018). In addition, GRHM cultivated by every employee brings development in the survival of living things on earth and brings the impact of sustainable development strategies in the work environment (Nijhawan, 2014).

GRHM will bring positive outcomes in the environment (Peerzadah et al., 2018). GRHM will also help resource management policymakers formulate and implement strategies to improve green purchasing in the future or the long term (Joshi \& Rahman, 2015). In an excellent company to increase GRHM, its employees can follow; 1) green employee acquisition, 2) green training, 3) green employee appraisal, 4) green rewards, 5) green discipline management, and 6) green health and safety (Amrutha \& Geetha, 2019). Some of them can be implemented in a company to improve the GRHM capability of employees. The main thing that needs to be given when providing training to employees is the ability to be aware of the environment and provide knowledge to employees on the environment in preventive solutions (Fernandez, Ana L, and Del-Rio, 2019).

This research's implication is the importance of implementing behavioral- 
based management startups and green lifestyles to create a production environment and preserve existing natural resources on earth (Hoogendoorn, Zwan, \& Thurik, 2020). If this can be realized, it will impact climate change that develops green space and can conduct healthy environmental development (Mabon, Kondo, Kanekiyo, Hayabuchi, \& Yamaguchi, 2019). Also, if GRHM can be combined with the green supply chain, it will produce a breakthrough both in creating a synergistic and integrative work environment in the world of management (Jabbour et al., 2016).

\section{CONCLUSION}

GRHM practice employees of PT. Cabot Indonesia has a high category. Most of the employees who were respondents in the study had undergraduate to doctoral education. Employees who have low GRHM practice do not exist at all, while those with a moderate category of $30.9 \%$. High-category employees dominated, at $69.4 \%$. It is certain that the employees at PT. Cabot Indonesia has implemented GRHM well. If the implementation of GRHM is good for its employees, then the work environment will be guaranteed environmental health and beauty.

\section{REFERENCES}

1. Amrutha, V. N., \& Geetha, S. N. (2019). A systematic review on green human resource management: Implications for social sustainability. Journal of Cleaner Production, 119131. https://doi.org/10. 1016/j.jclepro.2019.119131

2. Bansal, P., Roth, K., 2000. Why companies go green: a model of ecological responsiveness. Acad. Manag. J. 43, 717-736.

3. Confente, I., Scarpi, D., \& Russo, I. (2020). Marketing a new generation of bio-plastics products for a circular economy: The role of green self-identity, self-congruity, and perceived value. Journal of Business Research, 112(October 2019), 431-439. https://doi.org/10.1016/j.jbusres.2019.10.03 0

4. Fernandez, Ana L and Del-Rio, J. M. (2019). Green Human Resource Management. Responsible Consumption and Production, (January). https://doi.org/ 10.1007/978-3-319-71062-4

5. Flax, L., Kupers, R., \& Mons, B. (2020). Greening schoolyards - An urban resilience perspective. Cities, 106(June), 102890. https://doi.org/10.1016/j.cities.2020.102890

6. Hoogendoorn, B., Zwan, P. Van Der, \& Thurik, R. (2020). Goal heterogeneity at start-up : are greener start-ups more innovative? Research Policy, 49(10), 104061. https://doi.org/10. 1016/ j.respol. 2020.104061

7. Jabbour, C., Beatriz, A., Sousa, L. De, Jos, C., Sao, P., State, P., Bauru, Z. C. (2016). Green Human Resource Management and Green Supply Chain Management: linking two emerging agendas, 112, 1824-1833. https://doi.org/10.1016/j.jclepro.2015.01.05 2

8. Jena, S. K., \& Sarmah, S. P. (2015). Measurement of consumers' return intention index towards returning the used products. Journal of Cleaner Production, 108, 818829. https://doi.org/10.1016/j.jclepro. 2015. 05.115.

9. Joong, Y., Gon, W., Choi, H., \& Phetvaroon, K. (2019). International Journal of Hospitality Management The e ff ect of green human resource management on hotel employees' eco- friendly behavior and environmental performance. International Journal of Hospitality Management, 76 (April 2018), 83-93. https://doi.org/ 10. 1016/j.ijhm.2018.04.007

10. Joshi, Y., \& Rahman, Z. (2015). Factors Affecting Green Purchase Behaviour and Future Research Directions. International Strategic Management Review (Vol. 3). Holy Spirit University of Kaslik. https://doi.org/10.1016/j.ism.2015.04.001

11. Mabon, L., Kondo, K., Kanekiyo, H., Hayabuchi, Y., \& Yamaguchi, A. (2019). Fukuoka: Adapting to climate change through urban green space and the built environment? Cities, 93(March), 273-285. https://doi.org/10.1016/j.cities.2019.05.007

12. Nijhawan, G., Green HRM- A requirement for sustainable Organisation. ParipexIndian Journal of Research, 2014, 69-70.

13. Peerzadah, S. A., Mufti, S., \& Nazir, N. A. (2018). Green Human Resource Management: A Review, (October).

14. Úbeda-garcía, M., \& Claver-cort, E. (2021). Corporate social responsibility and firm performance in the hotel industry. The 
Wiwik Robiatul Adawiyah. The profile of Green Human Resource Management (GRHM) practices of employees in PT. CABOT Indonesia

mediating role of green human resource management and environmental outcomes, 123 (June2020), 57-69. https://doi.org/10. 1016/j.jbusres.2020.09.055

15. Val, P., \& Paill, P. (2020). Leveraging green human resource practices to achieve environmental sustainability, 260. https:// doi.org/10.1016/j.jclepro.2020.121137
How to cite this article: Wiwik Robiatul Adawiyah. The profile of Green Human Resource Management (GRHM) practices of employees in PT. CABOT Indonesia. International Journal of Research and Review. 2021; 8(2): 95-99. 